\title{
HUMAN BIOMONITORING RESEARCH AT DE MONTFORT UNIVERSITY: SCHOOL AND UNIVERSITY PARTICIPANTS' RECRUITMENT EXPERIENCE
}

\author{
A. Peña-Fernández ${ }^{1}$, N. Ali ${ }^{1}$, D. Millington ${ }^{2}$, M.C. Lobo-Bedmar ${ }^{3}$, P.I. Haris ${ }^{1}$ \\ ${ }^{1}$ De Montfort University, Faculty of Health and Life Sciences (UNITED KINGDOM) \\ ${ }^{2}$ De Montfort University, The Leicester School of Nursing (UNITED KINGDOM) \\ ${ }^{3}$ IMIDRA, Departamento de Investigación Agroambiental (SPAIN)
}

\begin{abstract}
Involving teachers in scientific research can increase schoolchildren's interest in studying science from an early stage which is critical to increase the numbers of high-school students studying scientific subjects. This will impact on the number of students enrolled in university science degrees to satisfy many basic human needs. A group of academics at De Montfort University (DMU, UK) have involved the Ravenhurst Primary School (RPS) in biomedical research, specifically a human biomonitoring (HBM) study involving schoolchildren (aged 6-9 years) and university students (aged 18-22 years) in Leicester (UK) to determine their nutritional status and exposure to metals. We have adopted a school-based approach to recruit participants from both educational arenas following the recommendations for executing HBM studies in Europe [1] with some modifications.
\end{abstract}

Permission from the school authorities was requested after gaining ethical approval from the DMU Research Ethics Committee (Ref. 1674). Parental/student consent was obtained by invitation and appointment letter, with the project details and ethical and data protection aspects written in simple language. Appropriately developed flyers, posters and information leaflets for each audience were also used to enhance the recruitment processes. Scheduling and facilitating flexible face-to-face appointments was critical for collecting the human samples needed for the project (urine and scalp hair) as well as comprehensive details about participants' diet and anthropometric measurements. The involvement of teachers and lecturers in conjunction with a registered general nurse (school nursing) was of paramount importance for achieving these goals, as they were encouraging participation throughout the process. During the appointments, parents and participants were debriefed in more detail about the project and the relevance of performing HBM to improve health in the community.

The school-based approach achieved the following results: a) the recruitment of a relevant number of participants (12 schoolchildren and 111 university students); b) the provision of a satisfying educational experience for parents, teachers/academics and participants in both educational arenas; c) the involvement of school-children in scientific research; d) the acquisition of awareness of the impact of environmental contamination by metals on human health; e) informing participants about their diets and body composition (e.g. percentage of body fat) promoting the necessity of adopting a healthy diet and lifestyle.

In conclusion, the project was successful in involving School teachers, University lecturers, schoolchildren, University students and community health workers in a research project. It provided an opportunity for educational development, promote staff motivation and students' interest and involvement in scientific research. Teachers updated their biomedical knowledge and skills by participating in this research and learnt new methods to engage schoolchildren (by promoting healthy lifestyles, protect the environment, etc.). This could help increase students' interest in studying science subjects at University and motivate them to embark on a future scientific career. Finally, the UK education system should do more to engage schools and teachers in performing scientific research and thereby make the scientific curriculum more practical that will facilitate students' learning and engagement.

Keywords: Involving teachers in research; lessons learned; human biomonitoring.

\section{INTRODUCTION}

Human biomonitoring (HBM) has been described as a reliable tool to protect human health, particularly to determine exposure to different toxicants including metals and metalloids due to their wide distribution in the environment [2-4]. HBM has also been described as an appropriate resource to 
compliment human health risk assessment and risk management, as HBM considers all exposure sources and the different ways of human uptake of toxicants [4]. Despite the relevance of HBM in detecting risks in the general public and as a tool for policy development to protect humans, only a few HBM studies have been performed in the United Kingdom (UK), particularly in young populations. Thus, Bevan et al. (2013) [5] reported that little is known about background levels of toxicants in general population in the UK, highlighting that previous publications reporting reference ranges for different metals and metalloids in the general UK population before them were limited to one by White and Sabbioni in 1998 [6]. The UK, in conjunction with different European countries, has recently initiated a European HBM project (Consortium to Perform Human Biomonitoring on a European Scale, COPHES) which has reported preliminary data about levels of mercury in hair and cadmium in urine in UK school-children and their mothers [7]

To address the current lack of knowledge of background levels of metals and metalloids in the healthy and unexposed English population, we have initiated a HBM study in the Biomedical and Environmental Health Research Laboratory at De Montfort University (DMU, Leicester, UK) to determine the background levels of these xenobiotics in hair and urine from children (aged 6-9 years) and young adults (University students aged 18-22 years) that live in Leicester (UK). To undertake this project, we have involved different teachers and staff at the Ravenhurst Primary School (RPS) in this biomedical research as well as different academics and healthcare personnel at DMU. One part of our HBM project also includes collection of nutritional information, anthropometric measures and other health-related data (such as for example blood pressure) to determine overall health and nutritional status. The above information is critical to establish guidelines and possible public health interventions to protect and improve public health in Leicester.

Different studies have highlighted that involving secondary school students in scientific research can increase students' interest in studying science from an early stage [8] and provides students with important outcomes such as promoting their learning of science and developing their confidence and efficacy [9]. In support of this idea, Chiovitti et al. (2017) [10] reported that involvement of secondary school children in science is critical to respond to future world global challenges. Moreover, teachers that work in university research have a myriad of positive outcomes including increased motivation and acquisition of skills to enhance their teaching methods and increase student engagement and satisfaction. Additionally, these teachers will be able to provide their students with the necessary skills to respond to future global challenges for which scientific knowledge is requested.

This paper will present the recruitment processes performed in 2015/16 and the main lessons learnt on engaging two different educational arenas in biomedical/public health research.

\section{METHODOLOGY}

We adopted a school-based approach to recruit participants from two educational arenas RPS and DMU during 2015 to 2016 following the recommendations for executing HBM studies in Europe [1] with some modifications. Other studies have undertaken this approach successfully from a recruitment point of view but with challenges particularly related with "convincing" the schools to participate in biomedical research studies [11-12].

Briefly, permission from the school authorities was requested after gaining ethical approval from the DMU Research Ethics Committee (Ref. 1674). Parental/student consent was obtained by invitation and appointment letter (Figure 1), with the project details and ethical and data protection aspects written in simple language. Appropriately developed flyers, posters and information leaflets for each audience were also used to enhance the recruitment processes (Figure 2). 


\section{PARTICIPANT INFORMATION SHEET}

Title of Project: Analysis of mineral elements in school-children (aged 6-9 years) in Leicester and assessment of their nutritional status.

\section{Name of Lead Investigator: Dr Antonio Peña Fernández}

As the parent/guardian of a child aged between 6-9 years, you have been invited to take part in a research study. Before you decide whether to take part it is important for you to understand why the research is being done and what it will involve. Please take time to read the following information carefully and discuss it with friends and relatives if you wish to. Ask us if there is anything that is not clear or if you would like more information. Take time to decide whether you wish to take part or not. Thank you for taking the time to consider taking part in this study.

\section{What is this study about?}

Low level, long-term exposure to toxic metals (minerals) is associated with a range of adverse health effects. In addition, nutritional deficiencies in essential minerals can facilitate the development of metabolic disorders and illnesses. Therefore, understanding the various factors that influence the metal burden of an individual, particularly children, is of critical importance to public health strategies. The main route of exposure to these substances is through the diet. Consequently, information concerning dietary intake is of the utmost importance in being able to assess risks to human health. This information will help to develop public health advice and strategies to improve the current and future health of children.

Figure 1. Detail of the information sheet used for recruitment in the primary school (RPS).

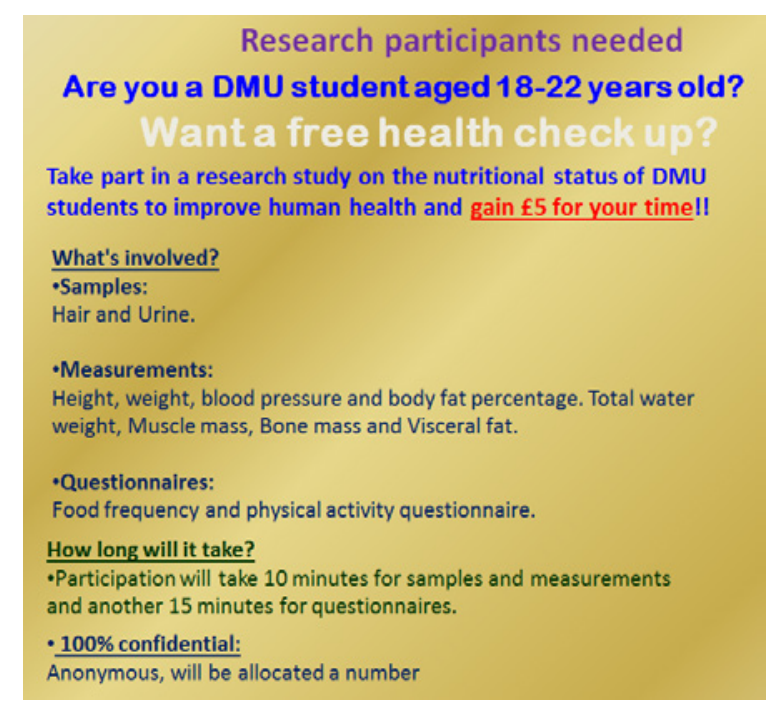

Figure 2. Detail of one of the posters used for recruitment.

We observed that facilitating flexible face-to-face appointments was necessary to encourage participation, especially for collection of samples (urine and scalp hair) and collect anthropometric measurements. Samples were collected following the methodology described by González-Muñoz et al. (2008) [13]; and we appointed a registered general nurse (school nursing) to collect samples and health data from children. During the appointments, parents and participants were debriefed in more detail about the project and the relevance of performing HBM to improve health in the community. A room was booked in both arenas for privacy purposes, particularly appropriate for collection of health data, e.g. blood pressure and anthropometric measures.

\section{RESULTS AND DISCUSSION}

In recent years the importance of engaging the public in science is being encouraged by learned societies and funding bodies although progress in this area is still limited. For example, the British 
Science Association (BSA) state that their "vision is of a future where science is seen as a fundamental part of culture and society at large, instead of set apart from it. Currently, science is seen as the domain of professionals and experts." [14]

The research findings presented in this article is an attempt to engage school children school teachers, parents, health care professionals and University researchers in a scientific research project. We recruited a number of participants particularly in the university arena (12 schoolchildren and 111 university students), therefore the school-based approach followed would be successful for recruiting participants in an educational arena.

The participation of a nurse and the establishment of effective communication with parents and teachers were of paramount importance for recruiting children. Potential strategies to increase participation could include changes in the school curriculum to offer the opportunity of engaging in bioscience research and providing teachers with the time acknowledged as continuing professional development activity. Despite generating controversy, providing an inducement to participate such as financial or material compensation to university participants showed an improvement in recruitment.

Moreover, the high number of tasks that participants needed to complete including a food frequency questionnaire and sports-activity questionnaire could have also impacted in the recruitment of participants in both settings.

The school-based approach used provided other benefits including the delivery of a satisfying educational experience for any person involved in the research (parents, teachers/academics and students) in both educational arenas. Participants also acquired awareness of the impact of environmental contamination by metals on their health as well as the necessity of adopting healthy diets and lifestyles.

Constraints of the school-based approach followed are mostly related with the fact that participation was a time-consuming and demanding process. Recruiting similar sample sizes from both sexes in both population groups was also challenge particularly for male participants as they showed less engagement in the study. Collection of hair samples in this group of the study population was also difficult due to their hair style, limiting the sample size for this biological matrix.

One of the limitations of our study was that only one primary school in Leicester was approached. This could increase the bias and is not sufficiently representative of the children population in Leicester. There are a myriad of possible factors that may limit the engagement of schools in research, including teachers with existing substantial workloads that discourage involvement in extracurricular activities. There are prevailing negative views about science in our society that needs to be countered through effective science communication and public engagement activities of the type we have conducted. Our results are in agreement with those published by other groups that have followed similar methodologies [1].

\section{CONCLUSIONS}

An overall analysis of the results collected so far has shown that our school-based approach was successful in engage schoolchildren, school teachers, parents, health care professionals and University researchers in a scientific research project. Teachers were provided with an opportunity for educational development and to increase their motivation. Teachers/academics that participated in this project updated their biomedical knowledge and learnt some methods to engage schoolchildren. Moreover, encouraging schools to be involved in university research could be an effective way to increase students' interest in undertaking a future scientific career.

These findings empower schoolchildren and teachers to engage in scientific research. However, the UK education system should consider being flexible and developing ways to incorporate the scientific curriculum in primary and secondary schools, to enhance teachers to be involved in university research.

\section{ACKNOWLEDGEMENTS}

The authors would like to thank Ravenhurst Primary School (RPS) including teachers, schoolchildren and the University students for participating in this study and particularly to David Swales, Deputy Headteacher at RPS. 


\section{REFERENCES}

[1] Fiddicke U, Becker K, Schwedler G, Seiwert M, Joas R, Joas A, et al. Lessons learnt on recruitment and fieldwork from a pilot European human biomonitoring survey. Environ Res. $2015 ; 141: 15-23$.

[2] Bocca B, Bena A, Pino A, D'Aversa J, Orengia M, et al. Human biomonitoring of metals in adults living near a waste-to-energy incinerator in ante-operam phase: Focus on reference values and health-based assessments. Environ Res 2016; 148:338-350.

[3] Haines DA, Saravanabhavan G, Werry K, Khoury C. An overview of human biomonitoring of environmental chemicals in the Canadian Health Measures Survey: 2007-2019. Int J Hyg Environ Health 2017; 220(2 Pt A):13-28.

[4] Schwedler G, Seiwert M, Fiddicke U, Ißleb S, Hölzer J, et al. Human biomonitoring pilot study DEMOCOPHES in Germany: Contribution to a harmonized European approach. Int J Hyg Environ Health 2017; 220(4):686-696.

[5] Bevan R, Jones K, Cocker J, Assem FL, Levy LS. Reference ranges for key biomarkers of chemical exposure within the UK population. Int J Hyg Environ Health 2013; 216(2):170-4.

[6] White MA. and Sabbioni E. Trace element reference values in tissues from inhabitants of the European Union. X. A study of 13 elements in blood and urine of a United Kingdom population. Sci Total Environ 1998; 216(3):253-270.

[7] Exley K, Aerts D, Biot P, Casteleyn L, Kolossa-Gehring M, Schwedler G, Castaño A, et al. Pilot study testing a European human biomonitoring framework for biomarkers of chemical exposure in children and their mothers: experiences in the UK. Environ Sci Pollut Res Int 2015; 22(20):15821-34.

[8] Pavesi G, Siccardi A, Viale G, Grazioli C, Calciolari T, Tenchini ML, Plevani P. Hedgehogs, humans and high-school science. The benefits of involving high-school students in university research. EMBO Rep 2008; 9(3):208-11.

[9] Sasson I. Participation in Research Apprenticeship Program: Issues Related to Career Choice in STEM. Int J Sci Math Educ 2018; available at: https://doi.org/10.1007/s10763-017-9873-8 [accessed 25/01/2018]

[10] Chiovitti A, Duncan JC, Jabbar A. Promoting Science in Secondary School Education. Trends Parasitol 2017; 33(6):416-420.

[11] Lytle LA, Johnson CC, Bachman K, Wambsgans K, Perry CL, Stone EJ, Budman S. Successful recruitment strategies for school-based health promotion: experiences from CATCH. J Sch Health 1994; 64(10):405-9.

[12] Phipatanakul W, Bailey A, Hoffman EB, Sheehan WJ, Lane JP, Baxi S, Rao D, Permaul P, Gaffin JM, Rogers CA, Muilenberg ML, Gold DR. The school inner-city asthma study: design, methods, and lessons learned. J Asthma 2011; 48(10):1007-14.

[13] González-Muñoz MJ., Peña A., Meseguer I. Monitoring heavy metal contents in food and hair in a sample of young Spanish subjects. Food and Chemical Toxicology 2008; 46:3048-3052.

[14] British Science Association. Our Vision. Available at: https://www.britishscienceassociation.org/vision [accessed 25/01/2018]. 